Article

\title{
An AHP Analysis on the Habitability Performance toward the Modernized Hanok in Korea
}

\author{
Mi-Hyang Lee, Deuk-Youm Cheon and Seung-Hoon Han * \\ School of Architecture, Chonnam National University, Gwangju 61186, Korea \\ * Correspondence: hshoon@jnu.ac.kr; Tel.: +82-62-530-1646
}

Received: 30 June 2019; Accepted: 29 July 2019; Published: 30 July 2019

\begin{abstract}
Hanok is a building style in Korean traditional architecture that presently supports a specialty of urban scenery and residential environment for regeneration in Korea. However, it is difficult to review or evaluate for the performance of Hanok, and there is no definite standard that can be applied to it yet. Therefore, it is necessary to establish the evaluation system of the residential performance of Hanok, and its concept model of the habitability performance needs to be derived in order to develop an evaluation system for the residential performance of Hanok. For this study, its evaluation factors have been classified into three major aspects such as the architectural space, the village complex, and the sustainability. This study, then, has attempted to build an evaluation system composed of proven assessment items or factors and performed AHP (Analytic Hierarchy Process) analyses with certified experts in the Hanok field and applied the relative importance among the evaluation items. Finally, this research has proposed an evaluation model of the habitability performance of Hanok. As a result of applying the assessment model for weighted habitability performances, the proposed evaluation system has been implemented as the inherent value of Hanok and its objectivity to be a major sustainable form of regeneration for contemporary residency in Korea.
\end{abstract}

Keywords: Hanok; Korean traditional house; residential performance; habitability; evaluation system; analytical hierarchy process; field survey

\section{Introduction}

In recent years, there has been a tendency toward the diffusion and activation of Hanok, a traditional Korean architectural style, as the atmosphere of society with a desire to satisfy cultural needs in Korea, and the overconcentration and high-rise of the city due to modernization, have led to a sudden shift in thought of habitation. It is likely that Hanok can represent a city landscape and can serve as an alternative to a new residential environment, at a time when social demands are increasing. Since securing cultural identity for the country is emerging as a new national competitiveness, there have been active projects to evaluate and preserve the value of traditional culture in each field.

Strandberg-de Bruijn, Donarelli and Balksten have insisted, through the case of historic Swedish timber buildings, that most historic single-family houses in Sweden, as shown on Figure 1a, have been constructed in either timber or brick, and the renovation of these buildings often focuses on using modern, vapor-tight insulation materials such as mineral wool and expanded polystyrene for external wall insulation to increase habitability [1]. Their concept is quite impressive and suggests that the main issue will be a need to improve the building performance of historic buildings with suitable materials compatible with the building framework, while preserving their character-defining elements. 


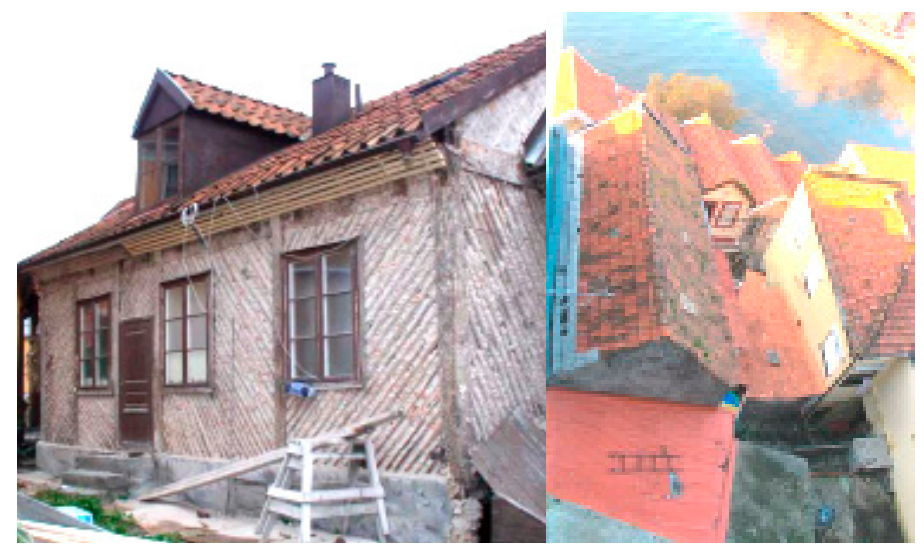

(a)

(b)

Figure 1. Examples for the habilitation work: (a) Exposed render on a renovated Swedish house (Source: Strandberg-de Bruijn et al., 2019); (b) Sustainable roof maintenance in the historic center of Porto (Source: Fernandes Rocha and Calejo Rodrigues, 1996).

An article by Fernandes Rocha and Calejo Rodrigues also investigated for the issue of the habitability of the traditional building in terms of maintenance. They said "one of the problems is precisely not knowing with any degree of accuracy the future performance of many construction materials and techniques, whereas maintenance must be one of the factors that enables predefined requirements to be ensured and helps guarantee their future in-service behavior under normal conditions," and suggested that the maintenance issue must be associated with rehabilitation solutions, even though the act of rehabilitation is often deprived of the required reasoning for the in-service performance of the solutions (See Figure 1b) [2].

Jeong, Cheon and Han raised another issue in maintenance and sustainability as a main factor of habitability, especially for Hanok, in their article titled 'A Better Maintenance Strategy, a More Sustainable Hanok: Towards Korean Traditional Public Facilities'. They emphasized that architecture has a duty in societies to preserve the past, provide the possibility of retaining the present on the strength of culture and tradition, and keep the performance with sufficient monitoring to see whether Hanok maintains its functions in the habitability accordingly [3].

Therefore, it is necessary to establish a multi-dimensional evaluation model in order to preserve Hanok's merits and own values as well as the performance factors. However, previous studies show a lack of combined concerns for the integrative assessment system, as applied to traditional buildings, and its detailed guidelines in terms of habitability and/or re-habitability. In other words, Hanok encloses human-oriented conscious objects such as history, tradition, place, image, memory and symbolism, and it is meaningful to search for the value of the settlement which has been discovered in the relationship between the environment and human beings [4]. So, it is expected that the possibility of Hanok can be improved through utilizing a comprehensive assessment system and considering the performance indexes based on its traditional values, such as habitability, recognized as one of the major merits of Hanok, especially when planning urban regeneration for old house blocks in Korea.

Traditional houses have a distinctive shape with such features as roof formation, and the building materials normally used, depending on the climate, lifestyle, environment and location of the country in which they are built. Each style reveals the architectural characteristics and internal meanings associated with the actual conditions of each region, including cultural individuality and peculiarity inherent in ethnicity and shapes in forms of the habitability. While they have unique features that vary from country to country, these houses also have general similarities in habitability due to their own natural environments with historical origins. For example, as Korean traditional houses were ordinarily built based on a village complex, traditional Malay houses called Kampong have been developed into a typical residential style in Southeast Asia as well. Generally speaking, Kampong 
means a village too and it is composed of several houses collectively with a mosque and common facilities such as schools, playgrounds, shops and so on [5].

Traditional Malay houses are mostly wooden buildings, and the high floor type structures derived from the local environment generally have many advantages related to climate control, such as ventilation and air-circulation. In addition, there are core features such as a rapid gradient gable roof, multi-purpose single space system, hierarchical settings of the space using step differences, space division according to gender, spatial openness and flexibility, and so on, as shown on Figures 2 and 3. In a previous investigation, Nasir and Wan have insisted, in the book entitled The Traditional Malay House, that the buildings in a Malayan village complex were built without physical boundaries to create an open atmosphere and are freely placed to increase the ventilation and air-circulation effects inside the buildings in the complex by staggering each physical house unit; this configuration is just like Hanok in aspects of the habitability of the traditional architecture. In addition, its versatility in the village complex and the architectural space also has a similar concept to Hanok, that focuses on the habitability emphasizing social relationship rather than personal life $[6,7]$.

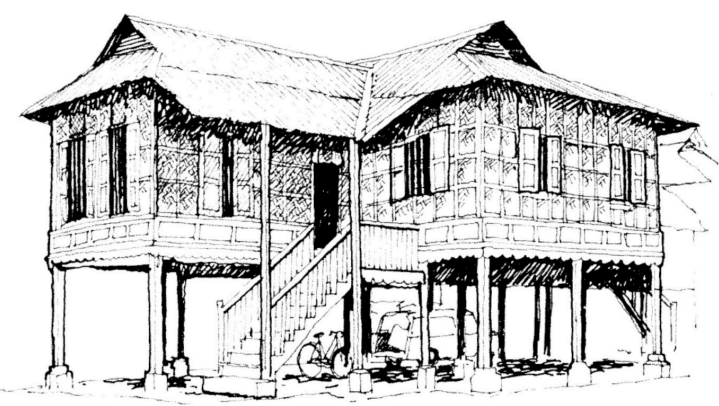

Figure 2. Fundamental design of the traditional Malay house (Source: Nasir, 1997).

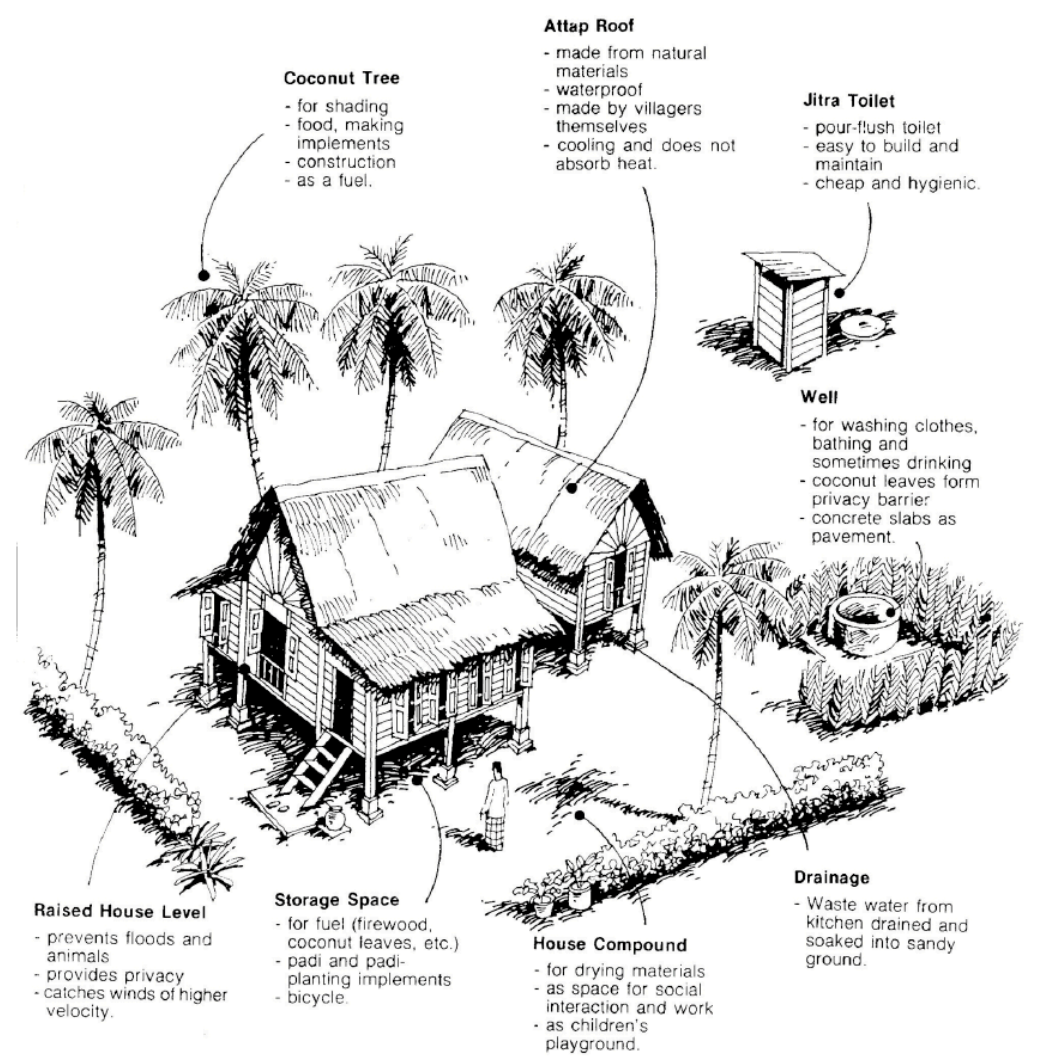

Figure 3. Habitability factors of the traditional Malay house (Source: Kamal et al., 2004). 
According to an article by Kamal, Wahab and Ahmad Asmalia C., the distinction between space use by gender was typical in Kampong, because Malayan people have traditionally adhered to customs and principles under Islamic culture; this situation was very similar to that of traditional Hanok in Korea. Generally, there is a small yard surrounded by trees and plants on the front of the Malay house, and there are many wells at the back. Trees and plants around the house are not just landscape elements, but are also an important factor influencing environmental sustainability in the interior space by providing shade for the house and coordinating the direction of the wind. They have also traditionally had differentiated staircases at the front and back entrances; the front one was mainly used by visitors and men, while the other was mostly for young children and women [7].

In response to this circumstance, regeneration includes repair, preservation and/or remodeling that have been carried out in various projects to realize new Hanoks or Hanok villages. From a practical point of view, it is also the current situation for determining the size of the building component and for implementing it by experience or intuition without any proper management during the construction of Hanok [8]. Despite the development of comprehensive architectural technology, it is difficult to estimate and evaluate the performance of Hanok due to the lack of clear standards that can be applied to it. In addition, according to Lee and Park, some critical issues for Hanok have also emerged, such as narrow space dimensions and the layout for a modern lifestyle, poor insulation, weak fire resistance, and expensive construction costs compared to contemporary buildings at present [9].

For this reason, the residential performance of Hanok is often recognized in terms of poor levels when evaluated against the standards for modernized buildings, because the existing evaluation system and certification criteria are mostly employed for Western types of housing. Figure 4 shows two different forms of Hanok: traditional and modernized. They have normal similarities in the external configuration, such as proportions and composites in aspects of aesthetics, while showing differences for performance factors such as insulation, air-tightness and so on.

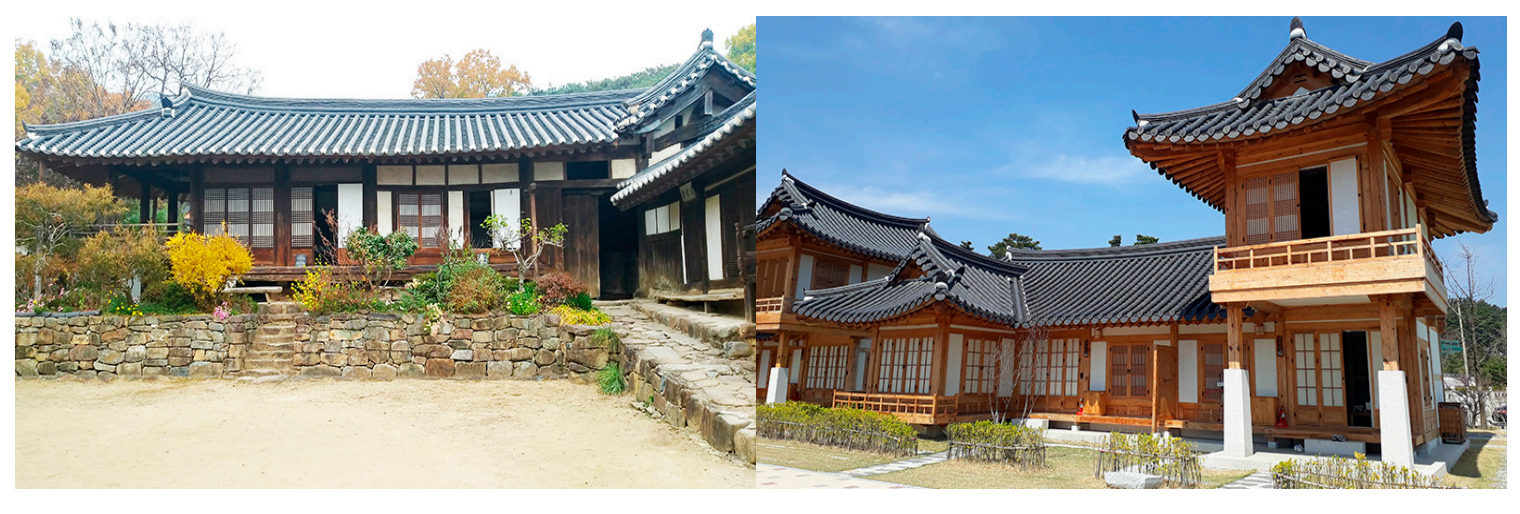

(a)

(b)

Figure 4. Typical Hanoks: (a) Traditional Hanok: Woonjoroo, Gurye, Chollanam-do, Korea; (b) Modernized Hanok: Gangreung, Gangwon-do, Korea.

Hanok certainly has unique characteristics and merits as an architectural style that retains Korean cultural identity and is a type of the architecture featuring both comfort and environmentally friendly performances. However, there are also many problems that need to be resolved, such as the structural performance, the energy capability, the environmental standard and the proper price required for contemporary housing while maintaining the used of conventional materials and the traditional construction methods [10]. Hanok is a settlement space constructed in accordance with the customs of the residents who have lived in communities from the past, that is, they are completed through various verifications according to local life. It is necessary to expand not only the visual and physical characteristics, but also the psychological and intrinsic space as the place of thought and ideology derived from residents as human beings [11]. 
The original Hanok has the continuity of all the building components forming the entire space and shows the spatial division by the upper and lower class systems in the same place. For instance, Anchae as the main residential space, and Sarangchae, a sort of the workplace, are places for the upper class, Hanrangchae functions as residences for the lower class, and the middle space such as Daechung or Maru is a type of hallway or lobby space connecting all the above different properties [12]. Hanok also encloses several outdoor spaces surrounded by fences to employ various yards that make them feel different with residents' spatial emotions whenever they touch each space every season. The characteristics of Hanok, therefore, can be analyzed with inherent values and conceptual characteristics contained in the house in terms of space. In addition, Hanok has asymmetrical and organically arranged planes on its own, but it has a visual balance in terms of the overall spatial layout. It has a strict hierarchy and/or a territoriality, but it is focused on the invisible order that seems to be free conceptually and inherent traditionally in it [13].

On the side of space connection, the enclosure expressed by the fence and the wing appears. The main door between a room and another can be an important object for the openness and the flexibility of the place, expressed in accord with the surrounding nature, the connecting gallery such as Daechung and the yard, and this is also a spatial extensibility shown from Hanok [14]. Furthermore, its continuity consists of a carpenter drawing, an outside distant view, a vertical level of the floor, a hierarchical structure of the space using the change of the stage, and a visual expansion of the space, and there is also a demarcation boundary and a superimposition which obscures the division of the space by opening and closing of the door [15].

For this reason, a precise analysis of Hanok characteristics is needed, as well as a standard for the performance evaluation, taking into consideration major evaluation indexes. The architectural characteristics such as spaces, proportions, materials and techniques are summarized in Figure 5.

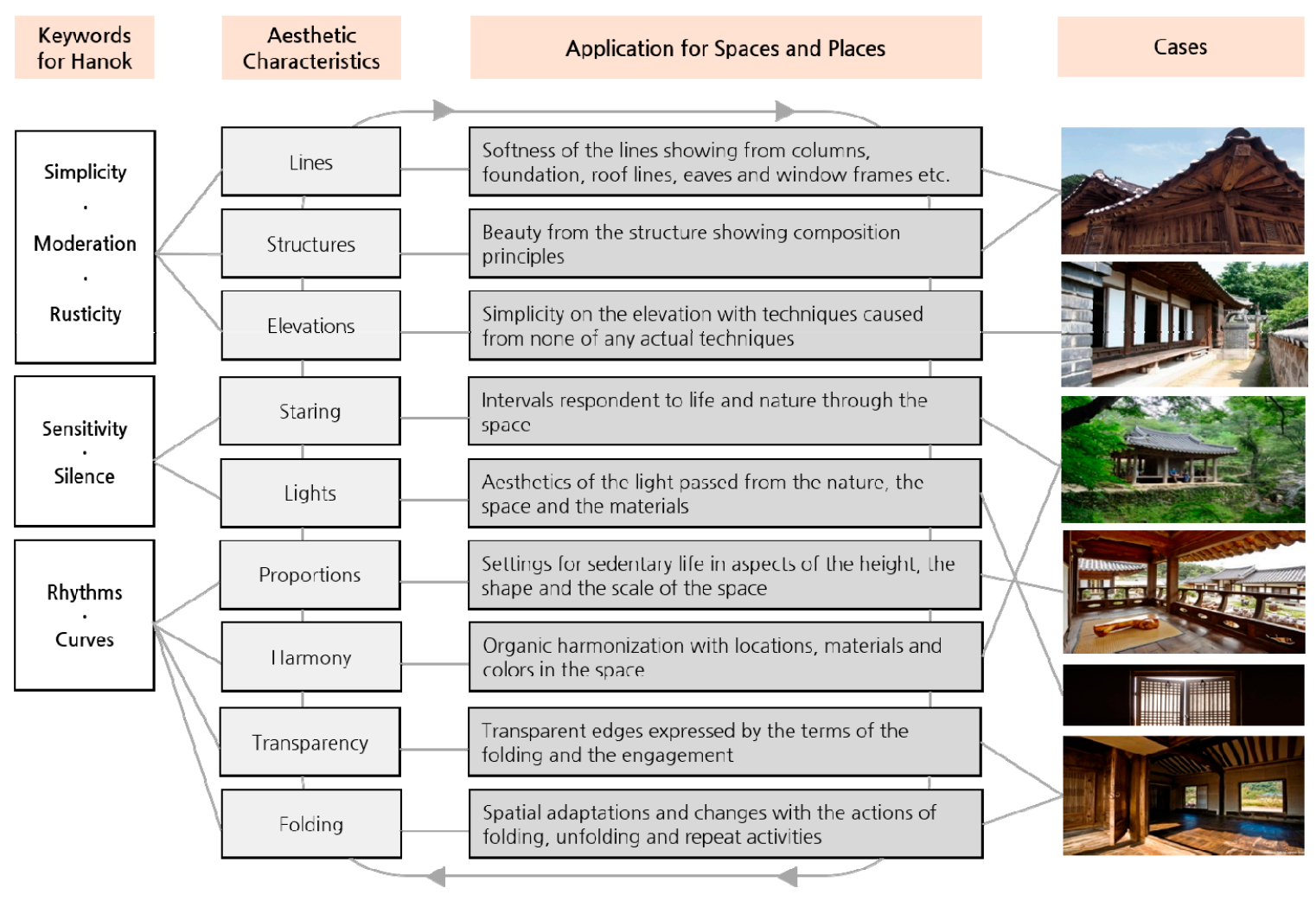

Figure 5. Hanok and its major characteristics.

In such a broad sense, architecture often reveals both the realization of the actual function, defined as a shelter, as well as cultural expression with specificity and universality historically and naturally in each country where villages and buildings are situated. It is clear that Hanok has been formed and 
understood in terms of habitability composed mainly of architectural spaces and village complexes. Their sustainability for the future implies actual human contexts and conditions similar to Malay architecture. However, it is true that studies on habitability and its succession and application into the architectural tradition towards modernization is fairly poor, while previous studies have often been limited to fundamental theories for spaces themselves. The elements and the evaluation system presented in this paper could provide a form of standard guidelines applicable to global settings for understanding general performances in habitability of traditional buildings, embodying their unique differences as well.

The purpose of this study is to improve the overall residential performance of Hanok by establishing the concept of its habitability functions that are distinguished from contemporary architecture and to present an assessment model for the performance, based on evaluation factors reflecting inherent characteristics as seen in Figure 6. From the standpoint of residents selecting Hanok as their residency, it is necessary to comprehensively judge and compare the performance of the building in terms of physical safety, spatial comfort, architectural environment and maintenance etc. If an evaluation model to classify indexes, standards, and methods related to the habitability performance in each field systematically, is developed as a tool for the purpose, it would be useful for consistently evaluating Hanok performance by practitioners and actual residents in Hanok.
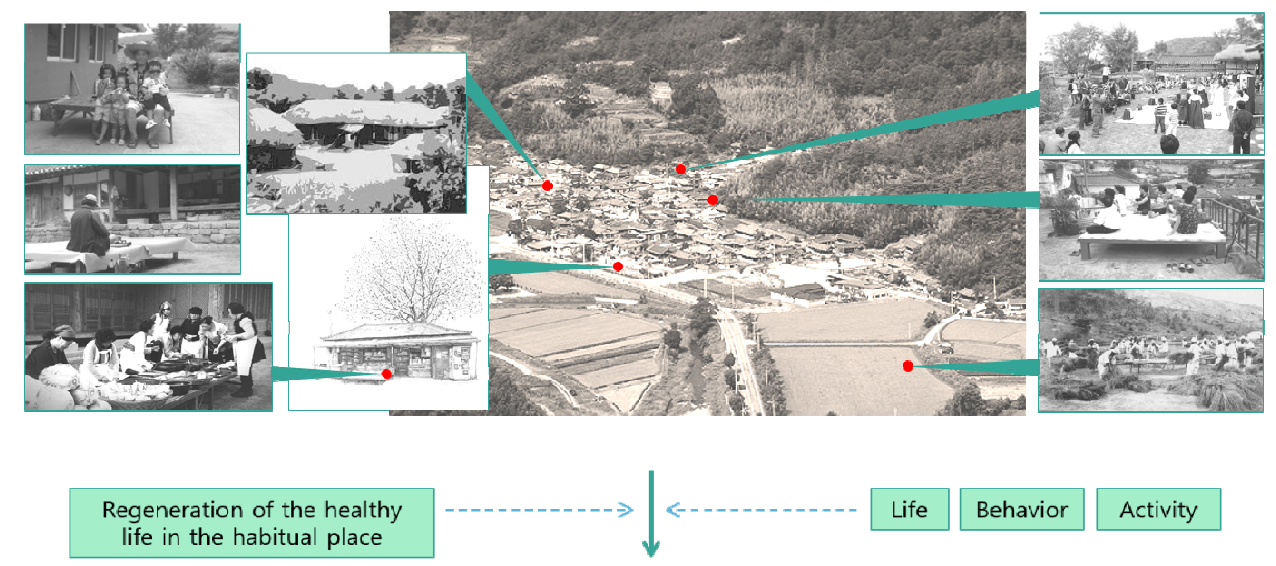

Habitability as Regeneration in Hanok

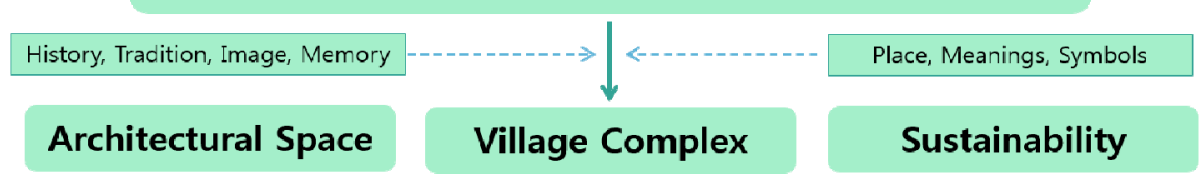

Figure 6. Hanok habitability as means of regeneration (Source: Lee, 2019).

\section{Methodology}

The versatile characteristics of Hanok habitability presented in the previous section are formed by the relationship between people who use the spaces and the places such as yard, room and floor, in such properties. Its transitional residential space naturally connects to the mediating spaces such as stairs, hallway, courtyard and veranda with the natural background around Hanok. In addition to these spatial features, many additional environmental values are fused together, which include physical and natural moods, living conditions for the residents, thoughts of the age, socio-cultural characteristics and so on [16].

All existing Hanoks can be described as traditional residences in Korea, but it is difficult to determined what makes good Hanoks. Although an evaluation standard for the building functionality can be used as a criterion to judge a Hanok, it is difficult to apply the criterion to determine which is officially better. 'The Upgrading Plan for Han-Style' operated by Korean Government and the policy 
objectives toward Hanok have been suggested and encouraged to be utilized by each local government, that focuses on promoting the qualified Hanok rather than on simply spreading it [17]. Therefore, the scope of Hanok is broad and an additional standard for qualifying Hanok is definitely needed. It is also required to improve its levels and values to meet quality and performance levels, so that Hanok can become an alternative form of housing in the construction and regeneration of residency [18].

Among the characteristics described above, the term habitability refers to human act or psychology for staying in a place as long as possible. In this definition, it is necessary to pay attention to what human beings are, what kind of mind they feel through the way of thinking, and what kind of space they love for the residency as the meaning of the place. It may be possible to create an environment for permanent living, if the characteristics of the user and the space revealed through it, are taken into consideration [19]. In previous research, the meaning of the term is expressed in various words such as residential values, satisfaction of the settlement and other, but its essential meaning is the value for the residence felt by the individual in the residency.

As also suggested by Ogunkah and Yang, there can be many factors that affect whether a planning method produced locally or globally is better for the natural surroundings, including the level of environmental impact, design suitability, economical effect, type of construction process, possible transportation and so on [20,21]. Karam M. Al-Obaidi and other authors also stated "a sustainable building can be achieved when it meets certain criteria such as the reduction of energy consumption, cost, and total embodied project energy" [22,23].

The latter can be achieved with a value system that has been consistently formed by many factors in habitability, including psychological, environmental and individual factors. This forms the fundamental value system in habitability [24]. This suggests that each residential user is different, and that the preference phase expressed by the values formed during the stay, may show similar tendencies, but are not exactly the same in the end. In addition, an investigation on current criteria for housing selection has tried to suggest three types based on concepts of the satisfaction factors when choosing houses, and it has analyzed how this concept influences the decision-making process of the residency preparation. As a result, the value of housing selection mainly affects the satisfaction and the preference toward housing, and the criteria of residency preparation is proportional to the value of housing selection. In other words, choosing houses positively affects the satisfaction and the preference about the housing, and the value of residential choice [25].

This study has suggested an evaluation model for the habitability performance that can be used for decision-making as a criterion to compare and judge by grasping the objective performance level of Hanok and also as a tool to disseminate and spread it. Even when performance evaluation is performed on the same object, its result will vary according to the field of interest of the resident respectively. A useful concept in deriving these results is a hierarchical structure of the performance evaluation, and the inside items for assessment are grouped into a single category and hierarchized, as demonstrated by Figure 7 .

Therefore, as the first step, evaluation items for the habitability performance were investigated through the previously developed models and related data analyses, and classified into hierarchical frames. The concept and purpose of each evaluation item has been analyzed to classify and organize the degree of mutual relations among precedent evaluation items. All assessment indexes for Hanok habitability are divided into three major categories, as repeatedly mentioned in the previous section. In addition, similar concepts are grouped into subcategories within the same major criteria for constructing a hierarchical frame. The items excluded from the existing evaluation model deemed deeply necessary were added to draw up a checklist for the performance evaluation through the review of current similar regulations.

As the next step in the selection of the evaluation items, duplicate ones with other items were checked for the index of sedentary performance factors and they were integrated for the dominant meaning. Then, the evaluation was conducted by combining expert opinions based on the principle of selecting evaluation items such as conformity to the purpose, importance of the evaluation item, 
easiness of assessment, possibility and objectivity for quantitative evaluation, and so on. In other words, the evaluation results can vary depending on the difference caused from the degree of the importance and residents' lifestyles, and the items can excessively be evaluated depending on the subjective view of the evaluator; the final items were determined after the exclusion of those items that are indicated in Table 1.

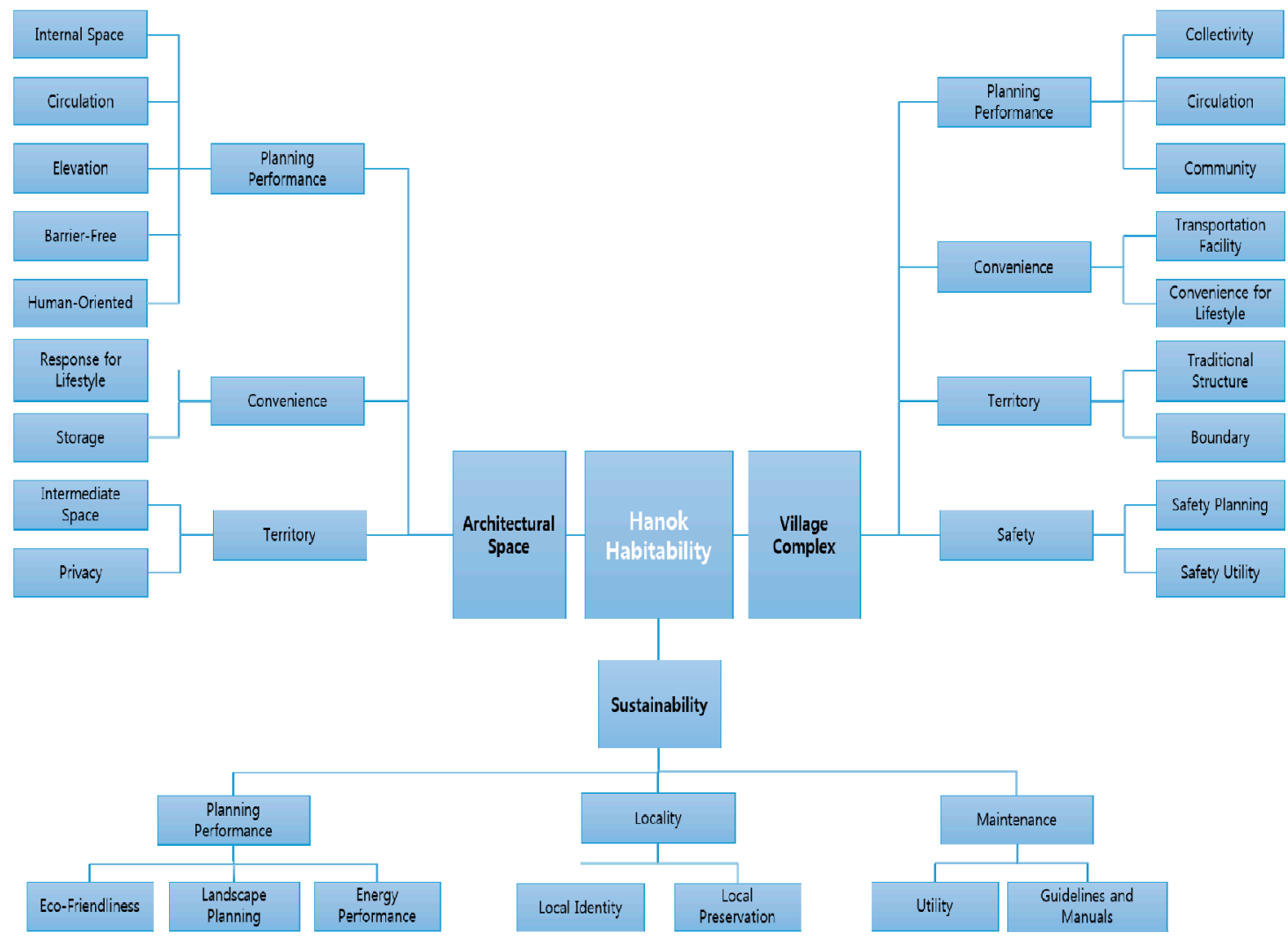

Figure 7. Hierarchical structure of Hanok habitability.

With this process, it is necessary to define the characteristic of Hanok and to establish an evaluation system with objectivity and reliability against qualitative factors. This research has set out to establish the evaluation system, perform feasibility analysis through onsite evaluations, determine importance setting of indicators for objectivity of the qualitative evaluation, and execute consistency verification. Considering the method of assigning the weight or the grade of each assessment item in the evaluation model for building performance, there is a case where the same weight value is uniformly given to all items.

However, it is true that differentiated weights are normally given in consideration of the relative importance of each item. In other words, a more rational direction can be sought by adjusting the weights among items so that the effect of the highest item in terms of relative importance on the total residence performance score, can be greater than that of the lower item [10]. The weighting or rating of each item may be different depending on the evaluation purpose and the characteristics of the building to be estimated, even though the same evaluation model is used. Nevertheless, it is more desirable to present the initial values and apply them to the situation accordingly. 
Table 1. Main categories and definitions of the evaluation indexes for Hanok habitability.

\begin{tabular}{|c|c|c|}
\hline \multirow{3}{*}{$\begin{array}{c}\text { Architectural } \\
\text { Space } \\
\text { I }\end{array}$} & $\begin{array}{c}\text { Planning } \\
\text { Performance }\end{array}$ & $\begin{array}{l}\text { Performance index for spatial needs of the residents to } \\
\text { be adapted to the space }\end{array}$ \\
\hline & $\begin{array}{c}\text { Convenience } \\
2\end{array}$ & $\begin{array}{l}\text { Spatial characteristics required for supporting } \\
\text { convenience of residents in architectural space }\end{array}$ \\
\hline & $\begin{array}{c}\text { Territory } \\
3\end{array}$ & $\begin{array}{l}\text { Satisfactory privacy of residents and spatial intervals } \\
\text { among residents in the space }\end{array}$ \\
\hline \multirow{4}{*}{$\begin{array}{c}\text { Village } \\
\text { Complex } \\
\text { II }\end{array}$} & $\begin{array}{c}\text { Planning } \\
\text { Performance }\end{array}$ & $\begin{array}{l}\text { Performance index for spatial needs of the residents to } \\
\text { be adapted to the place with surroundings }\end{array}$ \\
\hline & $\begin{array}{c}\text { Convenience } \\
2\end{array}$ & $\begin{array}{l}\text { Site characteristics required for planning performance } \\
\text { supporting convenience of village people }\end{array}$ \\
\hline & $\begin{array}{c}\text { Territory } \\
3\end{array}$ & $\begin{array}{l}\text { Satisfactory privacy of each resident in village } \\
\text { complex and spatial boundaries among spatial units }\end{array}$ \\
\hline & $\begin{array}{c}\text { Safety } \\
4\end{array}$ & $\begin{array}{l}\text { Spatial and utility elements for securing resident } \\
\text { safety from expecting disasters and crimes }\end{array}$ \\
\hline \multirow[t]{3}{*}{$\begin{array}{c}\text { Sustainability } \\
\text { III }\end{array}$} & $\begin{array}{c}\text { Planning } \\
\text { Performance }\end{array}$ & $\begin{array}{l}\text { Satisfactory sustainability applied to the village } \\
\text { complex and the spatial unit }\end{array}$ \\
\hline & $\begin{array}{l}\text { Locality } \\
2\end{array}$ & $\begin{array}{l}\text { Adaptation of urban context and local identity about } \\
\text { the village complex and the inside residences }\end{array}$ \\
\hline & $\begin{array}{l}\text { Maintenance } \\
3\end{array}$ & $\begin{array}{l}\text { Maintenance system and user guidelines for extending } \\
\text { the building lifecycle }\end{array}$ \\
\hline
\end{tabular}

The weight of each evaluation item applies a 5-point or 7-point Likert scale and the score of the evaluation item given as the total of 100 is statistically processed through a method of calculating the relative weight of each item through a questionnaire using Analytic Hierarchy Process (AHP). When using the Likert scale, the number of the questions to be answered by examinees can be smaller than the AHP method and it is normally easier to respond to the questionnaire $[10,26,27]$.

In a previous study, Guarini et al. mentioned that "the application of the AHP developed by Thomas Saaty allows to decompose the decisional problem, structuring hierarchic levels that allow to deal with the decision, reducing its complexity. Through the composition of a tree diagram, the general problem is divided in always smaller sets of the hierarchical structure, and the local priority between them is defined by pairwise comparisons" [28]. Saaty and Paola also said "starting from the AHP and its generalization to dependence and feedback, the analytic network process (ANP) comprise a well-known methodology that has been widely used for making the same kind of complex decisions needed here for choosing among the kind of cities to build, their design, location, and all the nuances involved in trading off different characteristics" [29].

However, they normally respond for equally-assigned grades without considering the relative importance among the questions, while the AHP technique has the advantage of reflecting each 
different importance assigned for all evaluation factors more accurately than by comparing them one by one, although the number of target questions is relatively high and often deemed difficult by examinees. According to the statement by Alshamrani et al., "since its introduction in 1980s, AHP alone, or combined with other techniques, has been extensively utilized to facilitate the selection process in many complex applications in the building industry. AHP divides a complicated problem into a simple and manageable hierarchy of factors" [30,31].

In particular, AHP can be very useful when the evaluation criterion has qualitative factors that cannot be measured objectively or quantitatively $[10,32,33]$. Therefore, the AHP technique has been employed for this study because of the characteristics for the evaluation items toward Hanok habitability and the hierarchical frame of the items, and because both of those have quantitative and qualitative aspects. For this study, the questionnaire survey for the weight calculation was conducted by ten chief architects with careers lasting more than ten years and ten Hanok experts who are licensed repair technicians for cultural properties, also with work careers for ten years or longer.

Unlike contemporary houses, where functional importance is more emphasized, Hanok has followed the principle of habitability when planned and built in a place. Its residents in the past bound their relationships to each other and joined together in a town to form one community and lived there for generations [32], when Hanok existed as the most representative type of Korean residency. Hanok residents themselves were able to maintain and manage their own lifestyle in an efficient manner simultaneously [26]. In this situation, the evaluation of the habitability performance for Hanok is by means of three aspects of the planning performance, namely the architectural space, the village complex and the sustainability. So, the overall evaluation for the habitability can be performed from qualitative points of view with subjective factors mostly.

One of the most efficient evaluation systems for the habitability utilized worldwide is the HQM (Home Quality Mark), as determined by the BRE (Building Research Establishment) in England. The HQM provides residents and housing buyers with more reasonable information about residential performance and supports effective guidelines for the professions in the field of AEC (Architecture, Engineering and Construction). This system also has categories and indexes for assessing habitual performance and uses the grading system based on the weights to differentiate the portion of each factor in the evaluation hierarchy as shown on Table 2 [34].

As a result of examining current cases of evaluation models for the residential building performance both in domestic and foreign regions, it was found that most of them have been utilized for assessing the degree of excellence in residency and determining the functional status to be reconstructed for regeneration in aspects of the safety followed by the diagnosis.

On the one hand, it has been possible to obtain the basic quality of the publicly or privately distributed residence by comparing its performance level with the legal standard or the accreditation level, and current evaluation models tend to be designed for the performance comparison. From the viewpoint of the building performance level to be evaluated in this way, it can be used to assess either building excellence or its performance. The evaluation model for the building performance is to estimate and compare the performance level of a target building with general technical levels that are currently being implemented for the purpose of setting standard regulations. This type is considered to be a representative evaluation model of the building aging with safety diagnosis.

On the other hand, the evaluation model for building excellence verifies the superiority of the performance for a target building using public authority by official institutions in more detail than the general building performance level [15]. Eco-friendly certification systems exemplified with domestic and foreign regulations implemented by public institutions are its representative examples. 
Table 2. Home Quality Mark: a case of the evaluation system in the area of the spatial habitability (Source: Home Quality Mark, 2015).

\begin{tabular}{|c|c|c|c|}
\hline Section & Category & Assessment Issue & Credits \\
\hline \multirow{8}{*}{ Our surroundings } & \multirow{3}{*}{ Transport and Movement } & 01 Accessible Public Transport & 16 \\
\hline & & 02 Alternative Sustainable Transport Options & 15 \\
\hline & & 03 Local Amenities & 19 \\
\hline & \multirow{2}{*}{ Outdoors } & 04 Ecology & 30 \\
\hline & & 05 Recreational Space & 20 \\
\hline & \multirow{3}{*}{ Safety and Resilience } & 06 Flood Risk & 18 \\
\hline & & 07 Managing the Impact of Rainfall & 16 \\
\hline & & 08 Security & 10 \\
\hline \multirow{17}{*}{ My Home } & \multirow{6}{*}{ Comfort } & 09 Indoor Pollutants & 10 \\
\hline & & 10 Daylight & 16 \\
\hline & & 11 Internal and External Noise & 4 \\
\hline & & 12 Sound Insulation & 8 \\
\hline & & 13 Temperature & 20 \\
\hline & & 14 Ventilation & 12 \\
\hline & \multirow{3}{*}{ Energy and Cost } & 15 Energy and cost & 62 \\
\hline & & 16 Decentralized Energy & 10 \\
\hline & & 17 Impact on Local Air Quality & 11 \\
\hline & \multirow{4}{*}{ Materials } & 18 Responsible sourcing of construction products & 31 \\
\hline & & $\begin{array}{l}19 \text { Environmental Impact from Construction } \\
\text { Products }\end{array}$ & 31 \\
\hline & & 20 Life Cycle Costing of Construction Products & 18 \\
\hline & & 21 Durability of Construction Products & 10 \\
\hline & \multirow{3}{*}{ Space } & 22 Drying Space & 3 \\
\hline & & 23 Access and Space & 10 \\
\hline & & 24 Recyclable Waste & 10 \\
\hline & Water & 25 Water Efficiency & 10 \\
\hline \multirow{10}{*}{ Knowledge Sharing } & \multirow{6}{*}{ Home Delivery } & 26 Commissioning and Performance & 10 \\
\hline & & 27 Quality Improvement & 10 \\
\hline & & 28 Considerate Construction & 4 \\
\hline & & 29 Construction Energy Use & 5 \\
\hline & & 30 Construction Water Use & 5 \\
\hline & & 31 Site Waste & 15 \\
\hline & \multirow{3}{*}{ User Experience } & 32 Aftercare & 10 \\
\hline & & 33 Home Information & 5 \\
\hline & & 34 Smart Homes & 7 \\
\hline & Future Learning & 35 Post-Occupancy Evaluation & 9 \\
\hline
\end{tabular}

\section{Results}

The participants in the AHP analyses for this study were interviewed one by one for each category and the evaluation items described in Table 1. Based on each relative importance, integer numbers from one to five and their reciprocal numbers are indicated on the questionnaire form and the results are applied to the weight calculation by AHP technique to derive the final weights of the evaluation items. In order to verify the validity of the survey results, the consistency ratio proposed by the AHP application was calculated and used to determine the reliability of the questionnaire. 
As a result of AHP analysis, the group of architectural experts answered that they should evaluate for overall performance factors of the settlement, and selected 'planning performance of the village complex' as the most important item, relatively, although there was not much difference. The planning performance of the architectural space in the middle category, and securing of the transition space in the subcategory were the most important choices. In particular, it was found that the village organization and image formed by the housekeeping rather than the single composition of Hanok was judged as the main factor of the habitability performance. The weights among the major items showed only a relatively small difference, and it seemed to reflect the job characteristics that emphasized the overall harmony of the planning aspects of Hanok.

In comparison, the Hanok expert group showed a somewhat contrasting result. Unlike the group of architects, who chose the overall factors, they regarded 'sustainable planning performance' as the most important factor. Items that achieved above average were also focused on the planning performance of sustainability and showed a difference with more than $20 \%$ from planning performance of the building space. Maintainability and facility management in the subcategory levels showed the highest importance in each category.

It was judged that the Hanok expert group valued its detailed compositions such as the form, the structure, and the finish. During the Focus Group Interview (FGI) with twenty evaluators, as seen in Figure 8 and Table 3, participants also pointed out that the planning performance is as fundamentally important as basic elements of the habitability performance, but that the maintenance and management performances are more important in the long run [35].

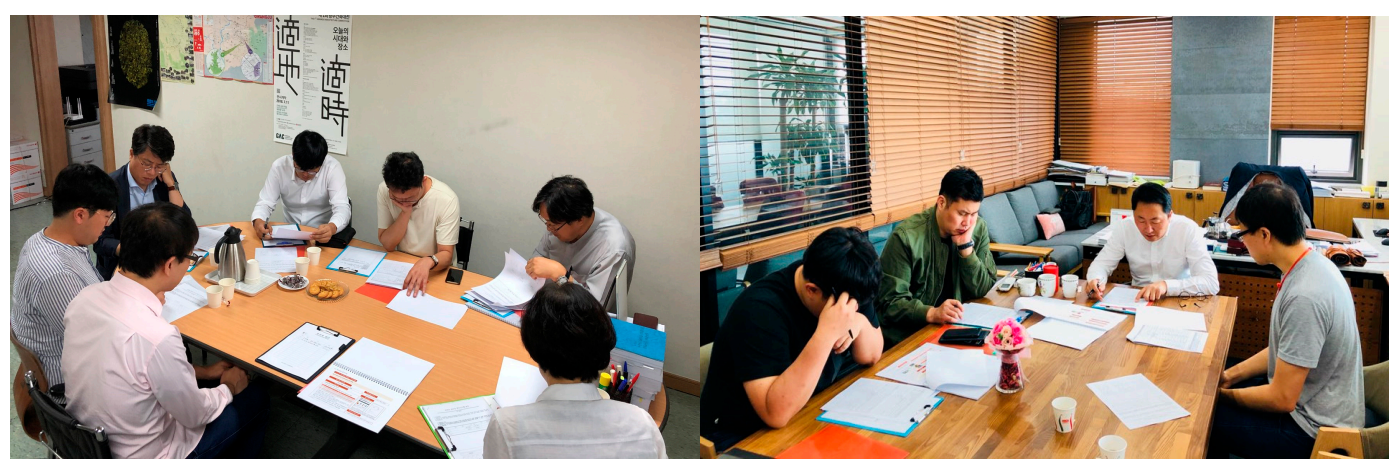

Figure 8. Analytic hierarchy process with focus group interview for experts (Source: Lee, 2019).

As a result of analyzing the two combined groups that held somewhat different positions for the final weighting as defined in Table 4, it has been shown that 'sustainable planning performance' was the most important. One of the reasons why the planning performance of the architectural space has relatively low importance is due to the differences in characteristics and scope of the work of each expert group, and this includes whether the overall planning is integrated or not in each field. In this way, this research has intended to incorporate all the different characteristics with the occupation type into the overall importance, and carried out onsite investigations and expert evaluations again to verify the reliability of the results from the AHP analyses. 
Table 3. Configuration of expert evaluation for Hanok habitability.

\begin{tabular}{|c|c|c|c|c|}
\hline \multicolumn{5}{|c|}{ Expert evaluators in the field of architecture (Group A) } \\
\hline No. & FGI Code (Date) & Expert Code & Affiliation & Position \\
\hline 1 & \multirow{5}{*}{$\begin{array}{c}\text { I } \\
(2018.09 .10 .)\end{array}$} & I-A & EL Architects & CEO, Registered Architect \\
\hline 2 & & $\mathrm{I}-\mathrm{B}$ & Ligaon Architects Co. & CEO, Registered Architect \\
\hline 3 & & $\mathrm{I}-\mathrm{C}$ & Loun Architects & CEO, Registered Architect \\
\hline 4 & & I-D & Design Group Geumseong Ltd. & CTO, Registered Architect \\
\hline 5 & & $\mathrm{I}-\mathrm{E}$ & Masil Architects & CEO, Registered Architect \\
\hline 6 & \multirow{5}{*}{$\begin{array}{c}\text { II } \\
(2018.09 .11 .)\end{array}$} & II-A & ISP Architects Co. & $\mathrm{CTO}$ \\
\hline 7 & & II-B & ISP Architects Co. & CEO, Registered Architect \\
\hline 8 & & II-C & One Architects Ltd. & CEO, Registered Architect \\
\hline 9 & & II-D & Bawoom Architects & CEO, Registered Architect \\
\hline 10 & & II-E & Eun Architects & CEO, Registered Architect \\
\hline \multicolumn{5}{|c|}{ Expert evaluators in the field of Hanok (Group B) } \\
\hline No. & FGI Code (Date) & Expert Code & Affiliation & Position \\
\hline 1 & \multirow{4}{*}{$\begin{array}{c}\text { III } \\
(2018.09 .17 .)\end{array}$} & III-A & Songdo Construction Co. & $\begin{array}{l}\text { Supervisor, Licensed } \\
\text { Technician }\end{array}$ \\
\hline 2 & & III-B & Songdo Construction Co. & Manager \\
\hline 3 & & III-C & Songdo Construction Co. & Vice Supervisor \\
\hline 4 & & III-D & Yido Construction and Industry Co. & Supervisor \\
\hline 5 & \multirow{3}{*}{$\begin{array}{c}\text { IV } \\
(2018.09 .18 .)\end{array}$} & IV-A & Cheongeoram R\&C Ltd. & Vice Supervisor \\
\hline 6 & & IV-B & Cheongeoram R\&C Ltd. & Manager, Licensed Technician \\
\hline 7 & & IV-C & $\begin{array}{c}\text { Korean National Institute of } \\
\text { Cultural Relics }\end{array}$ & Senior Researcher \\
\hline 8 & \multirow{3}{*}{$\begin{array}{c}\mathrm{V} \\
(2018.09 .19 .)\end{array}$} & V-A & Goguryeo Corporation & CTO \\
\hline 9 & & V-B & Handeul Corporation & CEO \\
\hline 10 & & $\mathrm{~V}-\mathrm{C}$ & Jingang Construction Co. & Supervisor \\
\hline
\end{tabular}

Through the analysis of the evaluation model for Hanok habitability performance, its assessment items have largely been classified into the architectural space, the village complex and the sustainability for setting evaluation methods for each element, example criteria and application weights. The evaluation index for the planning performance of the architectural space was divided into planning performance, convenience and territoriality, and has been utilized for assessing the appropriateness of the space arrangement and the scale of Hanok. It is evaluated by the expert checklist using architectural drawings for the performance evaluation with subjective scales to apply for the method of semantic difference, and weights are reflected to determine the final score.

Finally, evaluation indexes for the sustainability of Hanok are classified into three categories of the planning performance such as eco-friendly strategies, locality and maintenance performance, and composed of green building, landscape, energy, regional homogeneity, management, guidance and so on as assessment factors. As a result of AHP analysis for the expert group, the eco-friendly performance shows the highest importance among all the evaluation field and eventually, the strength of Hanok can be revealed though the process. In this procedure, qualitative evaluations could be reviewed at the planning stage, and maintenance status of the system has been suggested.

In order to evaluate the habitability performance of Hanok, detailed evaluation items have had to be verified by field surveys with the definition clarification of each item and its specific assessment method. Then, the suggested evaluation model was testified with onsite field surveys, and for this study, three original Hanoks described in Table 5 were considered for pilot tests with traditional heritage sites from Dorae Village in Naju, Korea, while three comparative contemporary Hanoks implemented by Hanok R\&D Group in Korea have been set for possible cases simultaneously. 
Table 4. Results from Analytic Hierarchy Process (AHP) analyses.

\begin{tabular}{|c|c|c|c|c|c|}
\hline \multirow{2}{*}{ No. } & \multirow{2}{*}{ Evaluation Criteria } & \multirow{2}{*}{$\begin{array}{l}\text { Importance in } \\
\text { the Hierarchy }\end{array}$} & \multirow{2}{*}{$\begin{array}{l}\text { Comprehensive } \\
\text { Importance }\end{array}$} & \multicolumn{2}{|c|}{ Inconstancy Ratio } \\
\hline & & & & Evaluated & Alternative \\
\hline Goals & \multicolumn{3}{|c|}{ Evaluation for Hanok Habitability } & 0.0057 & \\
\hline I & Architectural Space & $28.04 \%$ & $28.04 \%$ & 0.0001 & \\
\hline $\mathrm{I}-1$ & Planning Performance & $42.98 \%$ & $12.05 \%$ & 0.0031 & \\
\hline $\mathrm{I}-1-1$ & Internal Space & $21.97 \%$ & $2.65 \%$ & & 0 \\
\hline $\mathrm{I}-1-2$ & Circulation & $18.76 \%$ & $2.26 \%$ & & 0 \\
\hline $\mathrm{I}-1-3$ & Elevation & $11.17 \%$ & $1.35 \%$ & & 0 \\
\hline $\mathrm{I}-1-4$ & Barrier-Free & $18.43 \%$ & $2.22 \%$ & & 0 \\
\hline $\mathrm{I}-1-5$ & Human-Oriented & $29.67 \%$ & $3.58 \%$ & & 0 \\
\hline $\mathrm{I}-2$ & Convenience & $30.45 \%$ & $8.54 \%$ & 0 & \\
\hline $\mathrm{I}-2-1$ & Response for Lifestyle & $63.93 \%$ & $5.46 \%$ & & 0 \\
\hline $\mathrm{I}-2-2$ & Storage & $36.07 \%$ & $3.08 \%$ & & 0 \\
\hline $\mathrm{I}-3$ & Territory & $26.57 \%$ & $7.45 \%$ & 0 & \\
\hline $\mathrm{I}-3-1$ & Intermediate Space & $61.96 \%$ & $4.62 \%$ & & 0 \\
\hline $\mathrm{I}-3-2$ & Privacy & $38.04 \%$ & $2.83 \%$ & & 0 \\
\hline II & Village Complex & $34.35 \%$ & $34.35 \%$ & 0.0013 & \\
\hline II-1 & Planning Performance & $21.20 \%$ & $7.28 \%$ & 0.0008 & \\
\hline II-1-1 & Collectivity & $32.66 \%$ & $2.38 \%$ & & 0 \\
\hline II-1-2 & Circulation & $31.69 \%$ & $2.31 \%$ & & 0 \\
\hline II-1-3 & Community & $35.65 \%$ & $2.60 \%$ & & 0 \\
\hline II-2 & Convenience & $19.03 \%$ & $6.54 \%$ & 0 & \\
\hline II-2-1 & Transportation Facility & $43.67 \%$ & $2.85 \%$ & & 0 \\
\hline II-2-2 & Convenience for Lifestyle & $56.33 \%$ & $3.68 \%$ & & 0 \\
\hline II-3 & Territory & $25.95 \%$ & $8.91 \%$ & 0 & \\
\hline II-3-1 & Traditional Structure & $56.33 \%$ & $5.02 \%$ & & 0 \\
\hline II-3-2 & Boundary & $43.67 \%$ & $3.89 \%$ & & 0 \\
\hline $\mathrm{II}-4$ & Safety & $33.83 \%$ & $11.62 \%$ & 0 & \\
\hline II-4-1 & Safety Planning & $53.25 \%$ & $6.19 \%$ & & 0 \\
\hline II-4-2 & Safety Utility & $46.75 \%$ & $5.43 \%$ & & 0 \\
\hline III & Sustainability & $37.61 \%$ & $37.61 \%$ & 0.0072 & \\
\hline III-1 & Planning Performance & $37.52 \%$ & $14.11 \%$ & 0.0009 & \\
\hline III-1-1 & Eco-Friendliness & $32.17 \%$ & $4.54 \%$ & & 0 \\
\hline III-1-2 & Landscape Planning & $35.35 \%$ & $4.99 \%$ & & 0 \\
\hline III-1-3 & Energy Performance & $32.48 \%$ & $4.58 \%$ & & 0 \\
\hline III-2 & Locality & $30.21 \%$ & $11.36 \%$ & 0 & \\
\hline III-2-1 & Local Identity & $49.27 \%$ & $5.60 \%$ & & 0 \\
\hline III-2-2 & Local Preservation & $50.73 \%$ & $5.76 \%$ & & 0 \\
\hline III-3 & Maintenance & $32.27 \%$ & $12.14 \%$ & 0 & \\
\hline III-3-1 & Utility & $54.82 \%$ & $6.66 \%$ & & 0 \\
\hline III-3-2 & Guidelines and Manuals & $45.18 \%$ & $5.48 \%$ & & 0 \\
\hline
\end{tabular}


Table 5. Pilot Hanoks for comparative analyses with AHP.

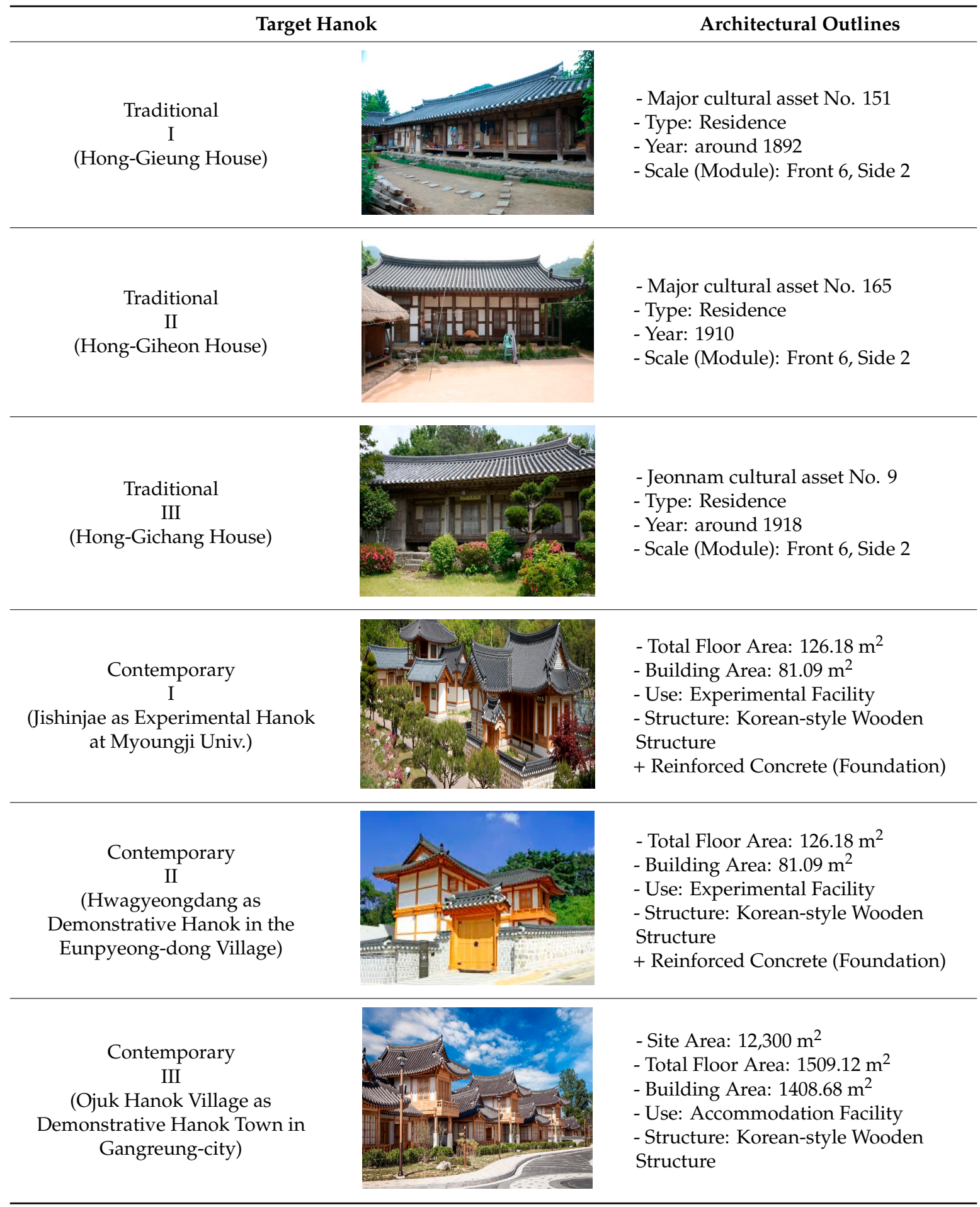

The habitability performance of Hanok could be evaluated accordingly for design strategies of space, circulation, elevation, barrier-free and human-centered elements after applying the AHP results for the target Hanoks. One of the main categories of the planning performance is convenience, which is a spatial characteristic required to provide efficient components for resident lifestyle in architectural spaces. Additionally, the spatiality of Hanok is divided into the section of users in the architectural space to secure privacy for everyone. The evaluation index of the planning performance for the village complex consists of nine factors under four categories such as planning performance, 
convenience, territorial property and safety. Evaluation of planning levels for community facilities include accessibilities to pedestrian pathways and public transportation facilities from the village and availability of supporting convenience properties for residents.

Since it is important to set up evaluation indexes for the habitability performance of customized Hanok residences, detailed questions on the checklists to be evaluated in the field are prepared, so that ordinary people living there can easily evaluate it. The checklist compiles and analyzes the residential performance using set evaluation indexes for existing houses to derive certified assessment factors according to the characteristics of Hanok. Simplification of checked items considering the user level and consistency of the evaluation items to facilitate the determination of the results have been examined. Furthermore, the assessment process has reflected the revisions such as additions and changes from the field test after the site survey, and it is planned to revisit each site, repeat the application and verify the procedures for the habitability performance with the proposed evaluation model to ensure reliability.

Because of the difference between the use at the time of planning and the current application in aspects of the habitability performance, there was no significant change before and after the application of the weighting for most cases, but the sustainability performance has been generously empowered. However, the characteristics that showed strength in the convenience of the village complex showed a tendency to be offset after weighting application.

In particular, in the case of the Hanok Village developed by the above mentioned group, the convenience and spatiality of the architectural performance that was an overwhelming strength showed on the first field evaluation, were decreased due to weighting, while the evaluation index of safety and sustainability aspects of the village complex increased overall [35]. The performance of the village complex and the sustainability performance were adjusted to each other. In this study, two major types of the target Hanok have been utilized for the analyses, as shown in Figure 9. Figure 10 shows the main comparative results between the two different processes. This study is currently conducting the evaluation for the habitability performance of Hanok with which weights are applied after the first field evaluation, and also the second investigation that will verify the reliability by overall field tests.

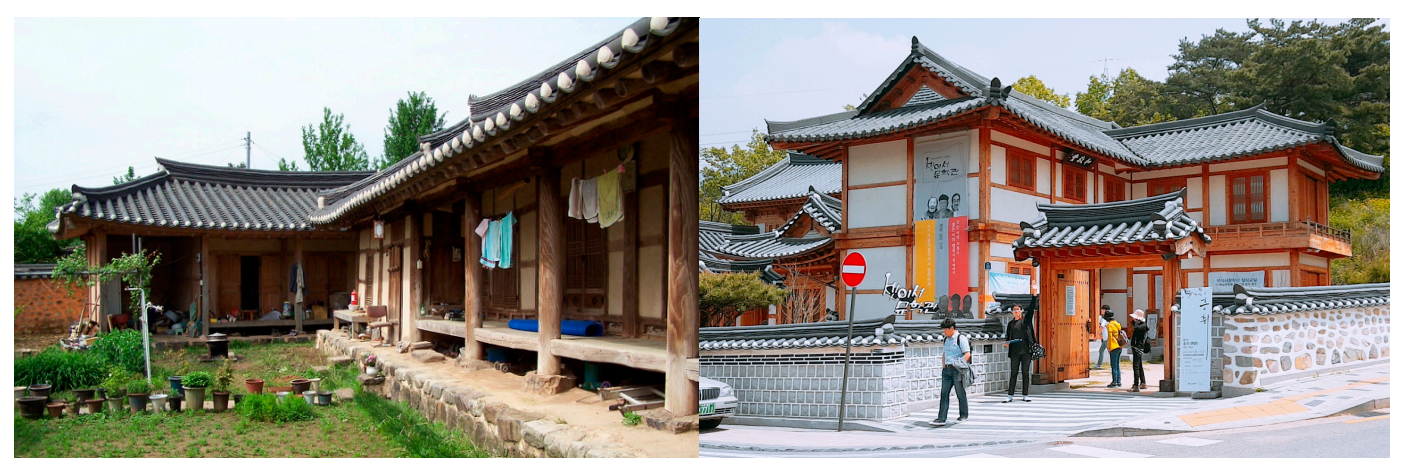

(a)

(b)

Figure 9. Structural differences between two types of target Hanoks: (a) Traditional target Hanok: Hong-Gieung House; (b) Modernized target Hanok: Hwagyeongdang (Source: Lee, 2019). 

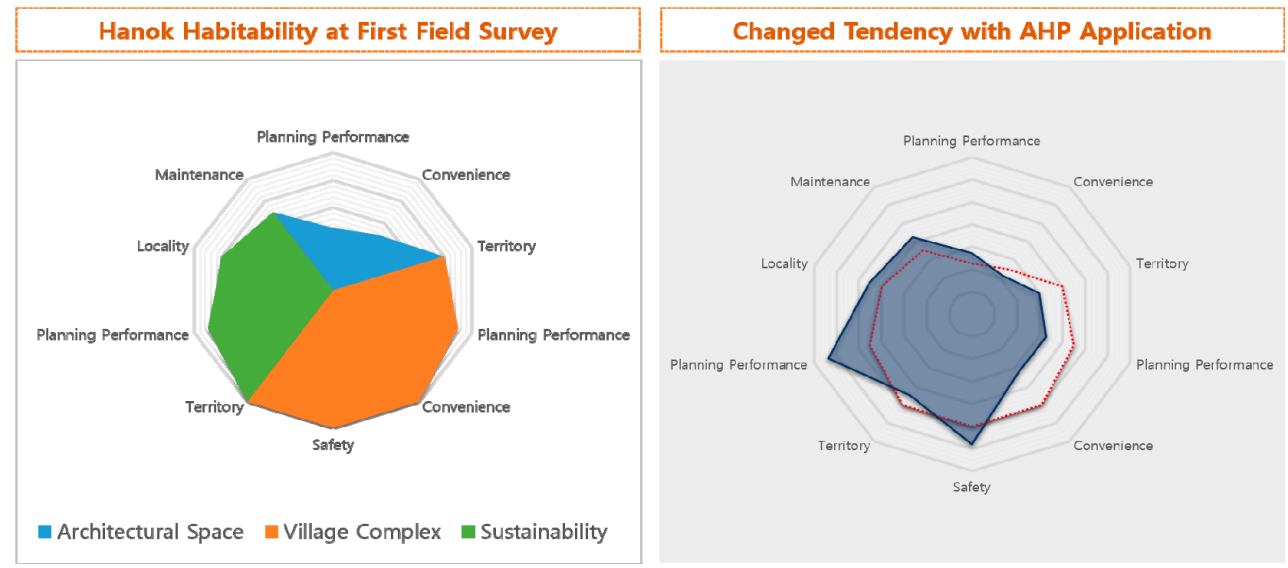

(a)

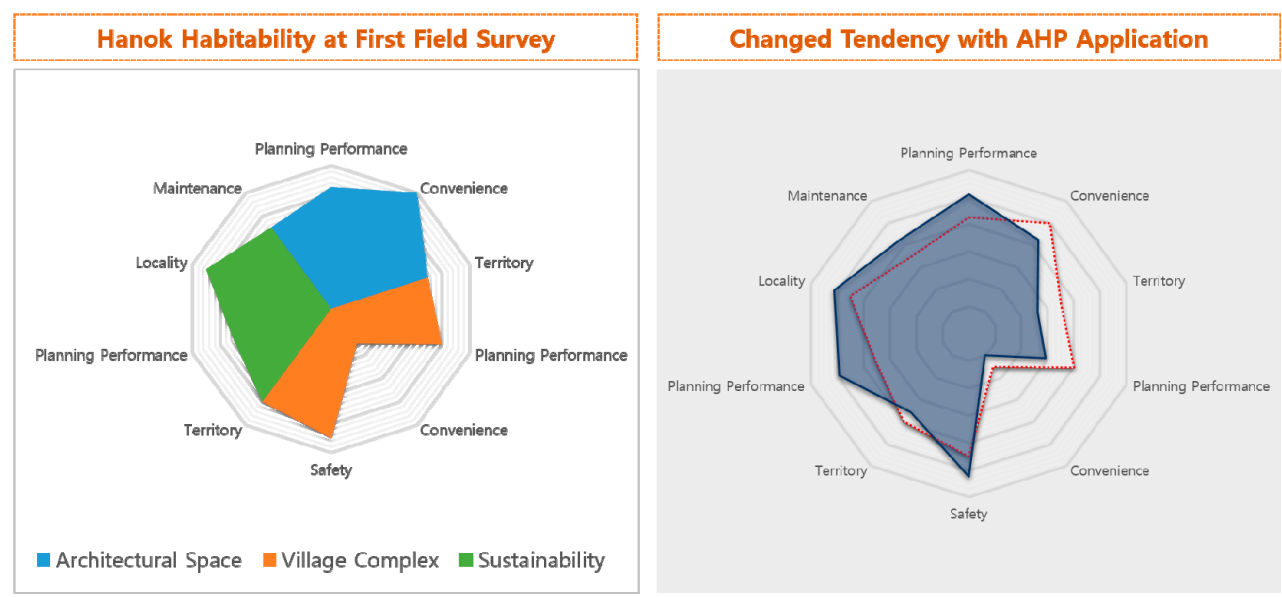

(b)

Figure 10. Comparative analysis results of the habitability performance showing trend changes with AHP application for a target Hanoks: (a) Distribution of habitability factors for Hong-Gieung House; (b) Distribution of habitability factors for Hwagyeongdang.

\section{Conclusions}

Hanok is an architectural type of Korean architecture that presents a variety of urban scenery and is likely to be an alternative to the new residential environment in Korea. However, it is not easy to satisfy the required performance based on the contemporary building while keeping it intact. Hanok is a habitual space and a human-oriented conscious place that is fulfilled with the culture, customs and regional emotions of residents staying in the community, because the intrinsic meaning is more important as an object of consciousness and ideology.

Therefore, it is necessary to establish the evaluation system of the residential performance, and it is urgent to establish a multidimensional evaluation model so that the merits and essence of Hanok can be kept for regeneration. In this study, the concept of habitability, which is the core value of residential performance of Hanok is established and its evaluation system has been implemented. In order to develop an evaluation model for performance of Hanok, its concept model of the habitability performance was derived, and the evaluation factors of the performance were classified into three representative aspects including the architectural space, the village complex and the sustainability. An evaluation checklist consisting of scales and eliminations for each evaluation item was prepared and onsite evaluations were conducted for excellence and applicability reviews.

This study has completed the evaluation system composed of proven evaluation items and performed AHP for experts, and applied the relative importance as weights among the evaluation items. Finally, this research proposed an evaluation model of the habitability performance of Hanok. 
Secondary onsite evaluation and expert verification have been conducted to verify the reliability and consistency of the evaluation model.

On the basis of the structured AHP, field trials were conducted with three traditional Hanoks and three regenerated ones. As a result of applying the final evaluation model of weighted habitability performance, the proposed evaluation system could successfully be utilized with the inherent value of Hanok and its objectivity to be a major sustainable form of the regeneration for contemporary residency in Korea. And, as exemplified with the case of Kampong, the Malay traditional building, the methodology proposed in this study could be utilized to review similar traditional architecture from other countries as well.

In the future, this study will conduct a reexamination with the experts to verify the reliability of the evaluation model, to standardize the evaluation criteria and to apply the guidelines to the practice. It is an important attempt to improve the quality of residence and rethink the value of the Hanoks by restoring the strengths of the traditional residence and regenerating its characteristics. Furthermore, the relationship between the habitual performance and the matching cost would be investigated and additional models to satisfy the economic benefits in the sense of LCC (Lifecycle Cost) could be suggested by future study. It would be meaningful for the succession, proper utilization and sustainable development of the unique architectural culture after all.

Author Contributions: M.-H.L., D.-Y.C. and S.-H.H. conceived and designed the field surveys; M.-H.L. and D.-Y.C. performed the evaluations; S.-H.H. analyzed the data; M.-H.L., D.-Y.C. and S.-H.H. wrote the paper.

Funding: This research was funded by Ministry of Land and Transport Affairs of Korean Government. (Project No.: 19AUDP-B128638-03).

Acknowledgments: This research was developed from Ph.D. dissertation by Mi-Hyang Lee and supported by a grant from Urban Architecture Research Program (Technology Development of Design and Construction for Large-Space Hanok over 10 Meters, Development of Hanok Technology, Phase III).

Conflicts of Interest: The authors declare no conflict of interest.

\section{References}

1. Strandberg-de Bruijn, P.; Donarelli, A.; Balksten, K. Full-scale Studies of Improving Energy Performance by Renovating Historic Swedish Timber Buildings with Hemp-lime. Appl. Sci. 2019, 9, 2484. [CrossRef]

2. Fernandes Rocha, P.; Calejo Rodrigues, R. Maintenance as a Guarantee for Roofing Performance in Buildings with Heritage Value. Buildings 2016, 6, 15. [CrossRef]

3. Jeong, J.-H.; Cheon, D.-Y.; Han, S.-H. A Better Maintenance Strategy, a More Sustainable Hanok: Towards Korean Traditional Public Facilities. Buildings 2019, 9, 11. [CrossRef]

4. Lee, M.-H.; Cheon, D.-Y.; Han, S.-H. Evaluation for the Residential Performance towards Restoration of Hanok Habitability. In Proceedings of the 2017 KAAH Fall Conference, Seoul, Korea, 18-19 November 2017.

5. Yeang, K. The Architecture of Malaysia; The Pepin Press: Amsterdam, The Netherlands, 1992; pp. 104-105.

6. Nasir, A.H.; Wan, W.H. The Traditional Malay House; Penerbit Fajar Bakti Sdn. Bhd.: Shah Alam, Malaysia, 1997; pp. 15-16. ISBN 978-9-67-653341-8.

7. Kamal, K.S.; Wahab, L.A.; Ahmad, A.C. Climatic Design of the Traditional Malay House to Meet the Requirements of Modern Living. In Proceedings of the 38th International Conference of Architectural Science Association, Launceston, TAS, Australia, 10-12 November 2004.

8. Kim, D.-K. Techniques and Applications of Design and Construction for Hanok. J. Korean Assoc. Archit. Hist. 2008, 17, 129-141.

9. Lee, J.; Park, J. Phase Change Material (PCM) Application in a Modernized Korean Traditional House (Hanok). Sustainability 2018, 10, 948. [CrossRef]

10. Han, S.-H.; Lee, M.-H.; Cheon, D.-Y. Assessment Indexes for Habitability Performances Applicable to Hanok Focused on Household Types. KIEAE J. 2018, 18, 5-14. [CrossRef]

11. Kim, D.-Y. Immateriality at the Upper-classes Residence in Chosun Dynasty. J. Reg. Assoc. Archit. Inst. Korea 2008, 10, 9-16.

12. Kim, S. A Study on Construction of Space and Design Elements of the Traditional Architecture Represented in Korea Hanok-Type Hotel. Master's Thesis, Daejin University, Pocheon, Korea, 2013. 
13. Kim, Y. Comparative Analysis on Interior Spaces of the Selected Historical Residences in the Western and Eastern Countries-Focusing on case residences of Korea, China, Japan, Rome, Egypt, and Italy. J. Korean Inst. Inter. Des. 2001, 27, 152-161.

14. Park, Y.; Hwang, T.; Kim, P. Effects of Housing Environment on Choice Criteria, Value, Satisfaction and Loyalty of Housing. J. Korean Assoc. Hous. Policy Stud. 2006, 14, 145-173.

15. Rhee, B.-H. The Typological Analysis of Space-Composition in the Traditional Korean Architecture. J. Archit. Inst. Korea 1998, 14, 183-193.

16. Min, S.-R.; Kim, T.-Y. A Study on the Attractive Items of Hanok in Urban Area focused on Preceding Studies. J. Korean Inst. Rural Archit. 2012, 14, 61-68.

17. Jeon, B.-H. A Study of Korean House Brands. J. Korean Stud. Inst. 2006, 8, 275-317.

18. Kim, S.; Kim, K.; Yang, I. Study on the Development of Housing Performance Evaluation Model for Multi-Unit Residential Buildings. J. Archit. Inst. Korea 2004, 20, 265-272.

19. Seo, S.; Um, S. An Empirical Study on the Determinant of Amenity in Daejeon Metropolitan. J. Korean Real Estate Soc. 2012, 30, 215-229.

20. Trusty, W.B. Understanding the Green Building Toolkit: Picking the Right Tool for the Job. In Proceedings of the USGBC Greenbuild Conference \& Expo, Pittsburgh, PA, USA, 12-14 November 2003; Available online: http://www.athenasmi.ca/publications/publications.html (accessed on 27 September 2010).

21. Ogunkah, I.; Yang, J. Investigating Factors Affecting Material Selection: The Impacts on Green Vernacular Building Materials in the Design-Decision Making Process. Buildings 2012, 2, 1-32. [CrossRef]

22. Department of the Environment and Heritage. Preserving Our Past, Building Our Future; Department of the Environment and Heritage: Canberra, Australia, 2004.

23. Al-Obaidi, K.; Wei, S.; Ismail, M.; Kam, K. Sustainable Building Assessment of Colonial Shop Houses after Adaptive Reuse in Kuala Lumpur. Buildings 2017, 7, 87. [CrossRef]

24. Ha, J. A Study on the Apartment Choice and Housing Satisfaction by the Type of Housing Value. J. Korean Hous. Assoc. 2007, 18, 11-20.

25. Park, S.; Jeong, M. Study on Space Sequence of Korean Traditional Residence from an Aesthetic Point of View. J. Archit. Inst. Korea 2006, 22, 119-126.

26. Lee, C.-J.; Choi, I. Post Occupancy Evaluation of Hanok in Rural Area and Comparative Study on the Perception of Hanok-Based on Hanok Residents and Architectural Designers Comparison. J. Korean Inst. Rural Archit. 2010, 12, 77-84.

27. Lee, M.-H.; Cheon, D.-Y.; Han, S.-H. An Evaluation for the Habitability Performance Toward Residential Space in Neo-Hanok. In Proceedings of the 2018 KAAH Fall Conference, Daejeon, Korea, 15-17 November 2018.

28. Guarini, M.; D'Addabbo, N.; Morano, P.; Tajani, F. Multi-Criteria Analysis in Compound Decision Processes: The AHP and the Architectural Competition for the Chamber of Deputies in Rome (Italy). Buildings 2017, 7, 38. [CrossRef]

29. Saaty, T.; De Paola, P. Rethinking Design and Urban Planning for the Cities of the Future. Buildings 2017, 7, 76. [CrossRef]

30. Lv, F.; Wang, Z.; Ding, Y.; Li, Y.; Zhu, N.A. Systematic Method for Evaluating the Effects of Efficient Lighting Projects in China. Energy Effic. 2016, 9, 1037-1052. [CrossRef]

31. Alshamrani, O.; Alshibani, A.; Alogaili, M. Analytic Hierarchy Process \& Multi Attribute Utility Theory Based Approach for the Selection of Lighting Systems in Residential Buildings: A Case Study. Buildings 2018, 8, 73. [CrossRef]

32. Kwon, Y. A Consumer Research for NEO-Hanok Maeul, Korean Traditional Style Village. J. Archit. Inst. Korea 2010, 26, 97-106.

33. Han, S.-H.; Im, O.-K.; Lee, M.; Cheon, D.-Y. A Study on the Establishment of an Evaluation System for Integrative Comfort. J. Korean House. Assoc. 2013, 24, 27-35. [CrossRef]

34. Home Quality Mark. Available online: www.homequalitymark.com (accessed on 15 April 2018).

35. Lee, M. Implementation of an Evaluation Model for the Habitability Performance of Hanok. Ph.D. Thesis, Chonnam National University, Kwangju, Korea, 2019.

(C) 2019 by the authors. Licensee MDPI, Basel, Switzerland. This article is an open access article distributed under the terms and conditions of the Creative Commons Attribution (CC BY) license (http://creativecommons.org/licenses/by/4.0/). 